\title{
Induced Marine Fungus Chondrostereum sp. as a Means of Producing New Sesquiterpenoids Chondrosterins I and $J$ by Using Glycerol as the Carbon Source
}

\section{Hou-Jin Li ${ }^{1}$, Wen-Han Jiang ${ }^{1}$, Wan-Ling Liang ${ }^{2}$, Jia-Xin Huang ${ }^{1}$, Yu-Fei Mo ${ }^{2}$, Yan-Qing Ding ${ }^{2}$, Chi-Keung Lam ${ }^{1}$, Xiao-Jun Qian ${ }^{3}$, Xiao-Feng Zhu ${ }^{3}$ and Wen-Jian Lan ${ }^{2,4, *}$}

1 School of Chemistry and Chemical Engineering, Sun Yat-Sen University, Guangzhou 510275, China; E-Mails: ceslhj@mail.sysu.edu.cn (H.-J.L.); natprodjwh@gmail.com (W.-H.J.); natprodhjx1@gmail.com (J.-X.H.); cklam@mail.sysu.edu.cn (C.-K.L.)

2 School of Pharmaceutical Sciences, Sun Yat-Sen University, Guangzhou 510006, China; E-Mails: natprodlw1@gmail.com (W.-L.L.); marinemyf@yahoo.com (Y.-F.M.); marinedyq@gmail.com (Y.-Q.D.)

3 State Key Laboratory of Oncology in South China, Cancer Center, Sun Yat-Sen University, Guangzhou 510060, China; E-Mails: marineqxj@gmail.com (X.-J.Q.); zhuxfeng@mail.sysu.edu.cn (X.-F.Z.)

4 Guangdong Technology Research Center for Advanced Chinese Medicine, Guangzhou 510006, China

* Author to whom correspondence should be addressed; E-Mail: lanwj@mail.sysu.edu.cn; Tel.: +86-20-39943042; Fax: +86-20-39943000.

Received: 1 November 2013; in revised form: 2 December 2013 / Accepted: 12 December 2013 / Published: 7 January 2014

\footnotetext{
Abstract: Chondrostereum sp., a marine fungus isolated from a soft coral Sarcophyton tortuosum, can yield hirsutane framework sesquiterpenoids. However, the metabolites profiles vary dramatically with the composition change of the culture media. This fungus was cultured in a liquid medium containing glycerol as the carbon source, and two new metabolites, chondrosterins I and J (1 and 2), were obtained. Their structures were elucidated primarily based on MS, NMR and X-ray single-crystal diffraction data. By comparison with the known hirsutane sesquiterpenoids, chondrosterins I and $\mathrm{J}$ have unique structural features, including a methyl was migrated from C-2 to C-6, and the methyl at C-3 was carboxylated. Compound 2 exhibited potent cytotoxic activities against the cancer cell lines $\mathrm{CNE}-1$ and $\mathrm{CNE}-2$ with the $\mathrm{IC}_{50}$ values of 1.32 and $0.56 \mu \mathrm{M}$.
} 
Keywords: marine fungus; Chondrostereum sp.; sesquiterpenoids; chondrosterins; cytotoxic activity

\section{Introduction}

The previous works on the metabolites of marine fungus Chondrostereum sp. afforded a series of new hirsutane sesquiterpenoids, including chondrosterins A (3)-F and hirsutanol E, together with the known compounds hirsutanols A (4), C, F, arthrosporone and incarnal (5) [1-3]. Chondrosterin A, hirsutanol A, and incarnal exhibited potent cytotoxic activities against various cancer cell lines. The anticancer molecular mechanisms investigation showed that hirsutanol A could induce apoptosis and autophagy via accumulation of reactive oxygen species (ROS) [4-6].

Chondrostereum sp. was previously cultured in glucose-peptone-yeast (GPY) and potato-dextrose (PD) media, containing glucose as the carbon source. Recently, the fungus grew in a GPY media, which using glycerol as the carbon source instead of glucose. The metabolite profiles were analyzed by HPLC, and the result showed that the constituent and content of the metabolites extract of glycerol-containing culture were distinct different from those previous glucose containing media (Supplementary Figure S1). Furthermore, the ethyl acetate extract of the culture broth showed significant cytotoxic activity. These preliminary findings suggest that fungus Chondrostereum $\mathrm{sp}$. grown in different carbon source media may produce more novel bioactive metabolites. The metabolite isolation of the marine fungus cultured in glycerol-containing media afforded two new sesquiterpenoids chondrosterins I and J (1 and 2, Figure 1). Herein, we report their isolation, structure elucidation, and cytotoxic activities evaluation.

Figure 1. Chemical structures of compounds 1-5.

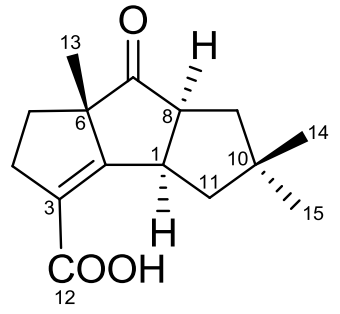

1

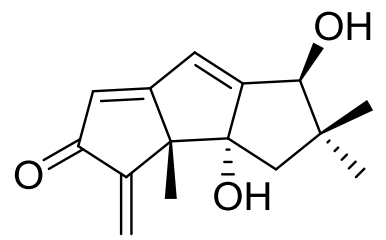

4<smiles>CC1(C)CC[C@@]2(C)C[C@@H](O)[C@H](O)[C@@H]2C1</smiles>

2<smiles>C=C1C(=O)C=C2C=C3C(=O)C(C)(C)C[C@]3(O)[C@]12C</smiles><smiles>C=C1C(=O)C=C2C[C@@]3(O)CC(C)(C)C[C@H]3[C@]12C</smiles>

3 


\section{Results and Discussion}

Chondrosterin I (1) was obtained as colorless solid. The molecular formula of $\mathbf{1}$ was established as $\mathrm{C}_{15} \mathrm{H}_{20} \mathrm{O}_{3}$ based on the HREIMS peak at $\mathrm{m} / z$ 248.1407 [M] ${ }^{+}$(Supplementary Figures S2 and S3) and ${ }^{13} \mathrm{C}$ NMR data (Table 1). In the IR spectrum, the prominent bands at 1736 and $1673 \mathrm{~cm}^{-1}$ indicated the presence of ketone carbonyl and carboxyl groups. The ${ }^{13} \mathrm{C}$ NMR and DEPT spectra displayed three methyls, four methylenes, two methines and six quaternary carbons (Supplementary Figures S4-S6). One carbonyl carbon $\left(\delta_{\mathrm{C}} 220.1\right)$, one carboxyl group $\left(\delta_{\mathrm{C}} 170.1\right)$, and one tetrasubstituted double bond ( $\delta_{\mathrm{C}} 169.9$ and 126.6), represented three double bond equivalents. Thus, 1 must be tricyclic to account for the six double bond equivalents required by the molecular formula. The UV maximum absorption at $244 \mathrm{~nm}$ indicated the tetrasubstituted double bond connected to the carboxyl group and formed a conjugated system. The cross-peaks of $\mathrm{H}-1 / \mathrm{H}-8, \mathrm{H}-1 / \mathrm{H}-11, \mathrm{H}-8 / \mathrm{H}-9$ and $\mathrm{H}-4 / \mathrm{H}-5$ in ${ }^{1} \mathrm{H}-{ }^{1} \mathrm{H}$ COSY showed the partial structures $-\mathrm{CH}_{2} \mathrm{CHCHCH}_{2}-$ and $-\mathrm{CH}_{2} \mathrm{CH}_{2}-$ in this molecule (Figure 2a, and Supplementary Figure S7). Three methyl groups with singlets were connected to quaternary carbons. Based on their HMBC correlations, two methyl groups with singlets at $\delta_{\mathrm{H}} 1.00$ and 1.14 were connected to quaternary carbon $\mathrm{C}-10\left(\delta_{\mathrm{C}} 43.5\right)$, the other methyl group with singlet at $\delta_{\mathrm{H}} 1.44$ was connected to C-6 $\left(\delta_{\mathrm{C}} 63.8\right)$. The HMBC correlations of H-1/C-2, H-1/C-8, H-4/C-3, H-4/C-12, H-5/C-6, H-8/C-7, H-9/C-10, H-13/C-7 established the planar structure of compound 1 (Supplementary Figure S8). The NOESY correlations of H-1/H-8, H-1/H-11 $\alpha\left(\delta_{\mathrm{H}} 2.03\right), \mathrm{H}-1 / \mathrm{H}-15\left(\delta_{\mathrm{H}} 1.00\right), \mathrm{H}-8 / \mathrm{H}-9 \alpha$ $\left(\delta_{\mathrm{H}} 2.03\right), \mathrm{H}-8 / \mathrm{H}-15$ (Figure $2 \mathrm{~b}$ ) established all these protons as $\alpha$-oriented. No NOESY correlation was observed between $\mathrm{H}-1 / \mathrm{H}-13$ and $\mathrm{H}-8 / \mathrm{H}-13$ indicated the methyl group $(\mathrm{H}-13)$ was placed at the $\beta$-oriented (Supplementary Figure S9).

Table 1. ${ }^{1} \mathrm{H}$ and ${ }^{13} \mathrm{C}$ NMR data for compound 1 obtained at $400 / 100 \mathrm{MHz}$, in $\mathrm{CDCl}_{3}$.

\begin{tabular}{ccc}
\hline Position & $\boldsymbol{\delta}_{\mathbf{C}}$, Type & $\boldsymbol{\delta}_{\mathbf{H}}$, Mult., $(\boldsymbol{J})$ \\
\hline 1 & $42.2, \mathrm{CH}$ & $3.96, \mathrm{ddd}(9.6,9.6,9.6)$ \\
2 & $169.9, \mathrm{C}$ & \\
3 & $126.6, \mathrm{C}$ & $\alpha: 1.99, \mathrm{~m} ; \beta: 1.85, \mathrm{~m}$ \\
4 & $32.5, \mathrm{CH}_{2}$ & $\alpha: 2.89$, ddd $(16.0,10.4,6.4) ; \beta: 2.72, \mathrm{dd}(16.0,8.8)$ \\
5 & $35.6, \mathrm{CH}_{2}$ & \\
6 & $63.8, \mathrm{C}$ & $3.22, \mathrm{ddd}(9.6,9.6,9.6)$ \\
7 & $220.1, \mathrm{C}$ & $\alpha: 2.03, \mathrm{~m} ; \beta: 1.68, \mathrm{~m}$ \\
8 & $58.2, \mathrm{CH}$ & $\alpha: 2.03, \mathrm{~m} ; \beta: 1.59, \mathrm{~m}$ \\
9 & $46.1, \mathrm{CH}_{2}$ & $1.44, \mathrm{~s}$ \\
10 & $43.5, \mathrm{C}$ & $1.14, \mathrm{~s}$ \\
11 & $46.1, \mathrm{CH}_{2}$ & $1.00, \mathrm{~s}$ \\
12 & $170.1, \mathrm{C}$ & $10.50, \mathrm{brs}$ \\
13 & $23.8, \mathrm{CH}_{3}$ & \\
14 & $28.2, \mathrm{CH}_{3}$ & \\
15 & $26.5, \mathrm{CH}_{3}$ & \\
$12-\mathrm{OH}$ & &
\end{tabular}


Figure 2. (a) ${ }^{1} \mathrm{H}-{ }^{1} \mathrm{H}$ COSY correlations (bold lines), the main HMBC correlations (arrows); and (b) key NOESY correlations for $\mathbf{1}$.

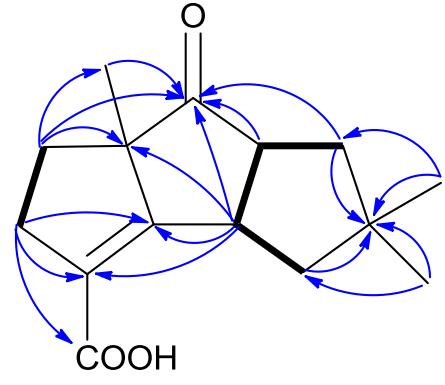

(a)

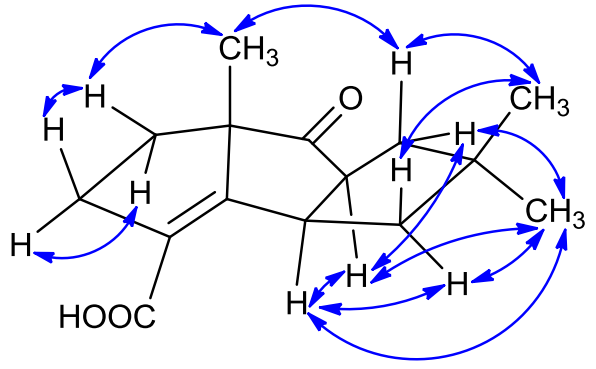

(b)

Circular dichroism (CD) spectrum of $\mathbf{1}$ exhibited a positive Cotton effect (Figure 3a). Having a cyclopentanone skeleton in this molecule, the octant rule was allowed to assign the absolute configuration. The absorption peak at $314.2 \mathrm{~nm}$ was due to an $n-\pi^{*}$ transition of the ketone group. The C-9, C-10, C-11, C-14 and C-15 resided in rear upper left and C-3, C-4, C-5 and C-12 located in rear lower right octants made significant positive contributions to the Cotton effect. So, the absolute configuration $1 R, 6 S, 8 S$ was determined. Finally, the structure of $\mathbf{1}$, and the absolute configuration $1 R$, $6 S$ and $8 S$ were confirmed by X-ray single-crystal diffraction data (Figure 4). The asymmetric unit contains two crystallographically independent molecules, which are joined together by a strong pair of $\mathrm{O}-\mathrm{H} . . . \mathrm{O}=\mathrm{C}$ hydrogen bonds and the crystal structure is further consolidated by weak $\mathrm{C}-\mathrm{H}$... $\mathrm{O}=\mathrm{C}$ intermolecular interactions.

Figure 3. Circular dichroism (CD) spectra of compounds 1 (a) and 2 (b).

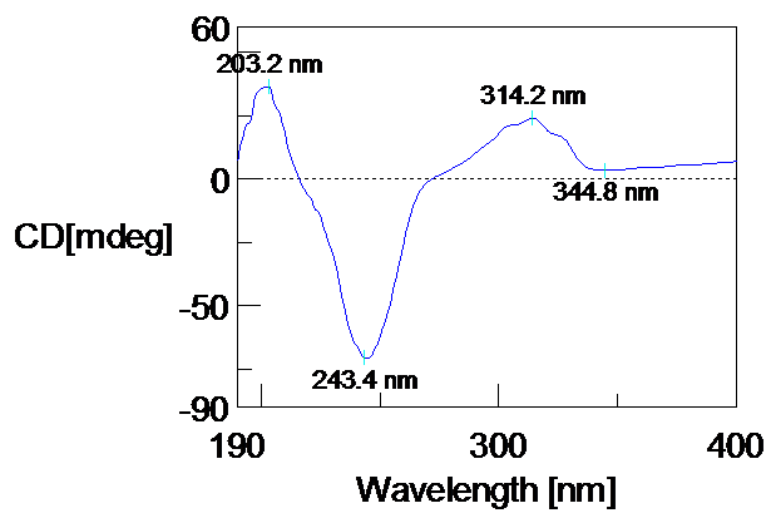

(a)

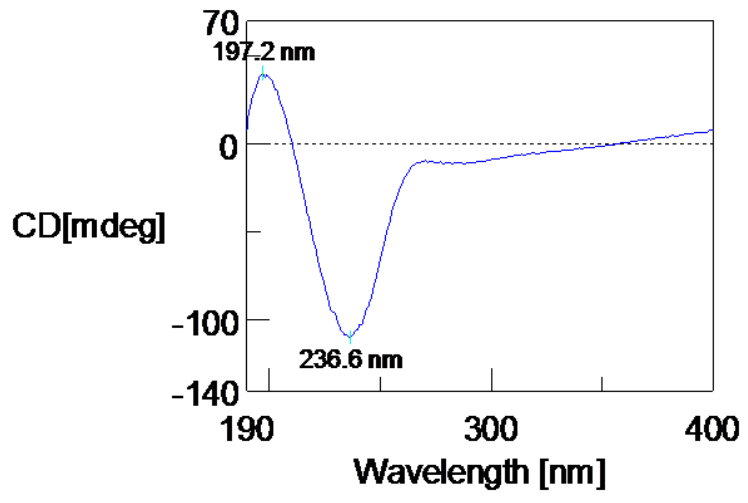

(b) 
Figure 4. Crystal structure of $\mathbf{1}$. Thermal ellipsoids are plotted at $30 \%$ probability level.

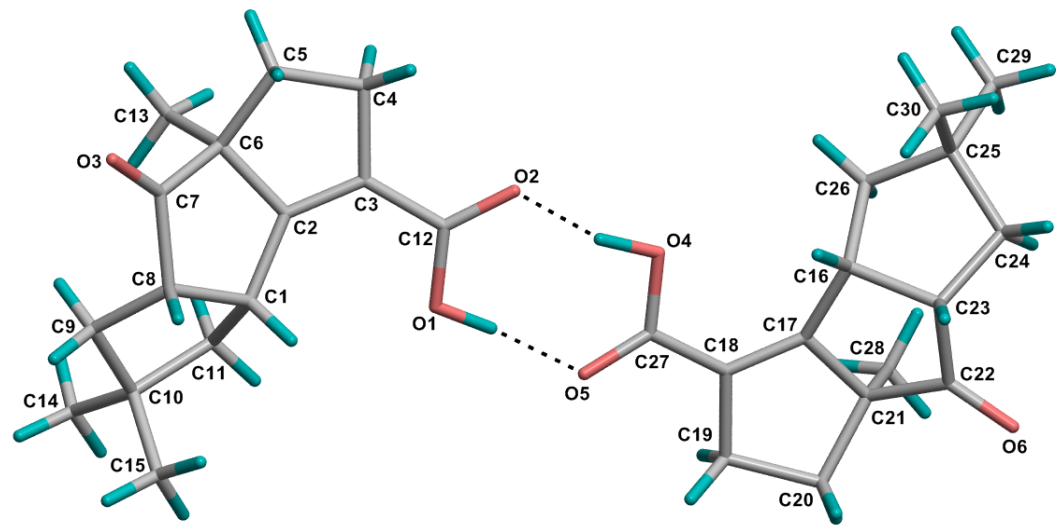

Table 2. ${ }^{1} \mathrm{H}$ and ${ }^{13} \mathrm{C}$ NMR data for compound 2 obtained at $400 / 100 \mathrm{MHz}$.

\begin{tabular}{|c|c|c|c|c|}
\hline Position & $\delta_{C}$, Type $^{a}$ & $\delta_{\mathrm{H}}$, Mult., $(J)^{\mathrm{a}}$ & $\boldsymbol{\delta}_{\mathrm{C}}^{\mathbf{b}}$ & $\delta_{\mathrm{H}}$, Mult., $(J)^{\mathbf{b}}$ \\
\hline 1 & $42.1, \mathrm{CH}$ & 3.55, ddd $(9.6,9.6,9.6)$ & 42.6 & 3.53, ddd $(9.6,9.6,9.2)$ \\
\hline 2 & $175.6, \mathrm{C}$ & & 173.7 & \\
\hline 3 & $123.4, \mathrm{C}$ & & 124.5 & \\
\hline 4 & $33.8, \mathrm{CH}_{2}$ & $\begin{array}{c}\alpha: 2.86, \operatorname{ddd}(15.6,9.6,6.4) \\
\beta: 2.71, \operatorname{dd}(15.6,6.0)\end{array}$ & 34.9 & $\begin{array}{c}\alpha: 2.80, \operatorname{ddd}(15.2,10.8,6.8) ; \\
\beta: 2.62, \operatorname{dd}(15.2,8.0)\end{array}$ \\
\hline 5 & $41.2, \mathrm{CH}_{2}$ & $\begin{array}{l}\alpha: 1.84, \mathrm{~m} \\
\beta: 1.75, \mathrm{~m}\end{array}$ & 42.3 & $\begin{array}{l}\alpha: 1.75, \mathrm{~m} \\
\beta: 1.70, \mathrm{~m}\end{array}$ \\
\hline 6 & $61.4, \mathrm{C}$ & & 62.1 & \\
\hline 7 & $79.0, \mathrm{CH}$ & $4.05, \mathrm{~d}(9.6)$ & 79.1 & $3.99, \mathrm{~d}(9.2)$ \\
\hline 8 & $51.9, \mathrm{CH}$ & 3.21, dddd $(9.6,9.6,9.6,6.8)$ & 53.0 & 3.17 , dddd $(9.2,9.2,9.2,9.2)$ \\
\hline 9 & $42.1, \mathrm{CH}_{2}$ & $\begin{array}{c}\alpha: 1.81, \text { dd }(12.0,6.8) \\
\beta: 1.48, \text { ddd }(12.0,9.6,2.0)\end{array}$ & 43.3 & $\begin{array}{c}\alpha: 1.97, \text { dd }(12.0,9.2) \\
\beta: 1.42, \text { ddd }(12.0,9.2,2.0)\end{array}$ \\
\hline 10 & $41.9, \mathrm{C}$ & & 42.2 & \\
\hline 11 & $46.6, \mathrm{CH}_{2}$ & $\begin{array}{c}\alpha: 2.00, \operatorname{ddd}(12.8,9.6,2.0) \\
\beta: 1.38, \text { dd }(12.8,9.6)\end{array}$ & 47.6 & $\begin{array}{c}\alpha: 1.92, \operatorname{ddd}(12.8,9.6,2.0) \\
\beta: 1.38, \operatorname{dd}(12.8,9.6)\end{array}$ \\
\hline 12 & $170.6, \mathrm{C}$ & & 166.7 & \\
\hline 13 & $18.5, \mathrm{CH}_{3}$ & $1.25, \mathrm{~s}$ & 19.2 & $1.24, \mathrm{~s}$ \\
\hline 14 & $28.7, \mathrm{CH}_{3}$ & $1.11, \mathrm{~s}$ & 29.3 & $1.09, \mathrm{~s}$ \\
\hline 15 & 26.6, $\mathrm{CH}_{3}$ & $0.97, \mathrm{~s}$ & 27.2 & $0.95, \mathrm{~s}$ \\
\hline 7-OH & & $4.92, \mathrm{brs}$ & & 3.84, brs \\
\hline $12-\mathrm{OH}$ & & 10.53, brs & & 10.47, brs \\
\hline
\end{tabular}

Chondrosterin J (2) was obtained as white solid. The molecular formula of $\mathbf{2}$ was established as $\mathrm{C}_{15} \mathrm{H}_{22} \mathrm{O}_{3}$ based on the HREIMS peak at $\mathrm{m} / \mathrm{z} \quad 250.1563[\mathrm{M}]^{+}$and ${ }^{13} \mathrm{C}$ NMR data (Table 2, Supplementary Figures S10-S13). The two broad singlets at $\delta_{\mathrm{H}} 4.92$ and 10.53 indicated there were two hydroxyl groups in this molecule. The ${ }^{13} \mathrm{C}$ NMR and DEPT spectra displayed three methyls, four methylenes, three methines and five quaternary carbons. One carboxyl group $\left(\delta_{\mathrm{C}} 170.6\right)$, and one tetrasubstituted double bond $\left(\delta_{\mathrm{C}} 175.6\right.$ and 123.4), represented two degrees of unsaturation. Thus, 2 must be tricyclic to account for the five degrees of unsaturation required by the molecular formula. By 
comprehensive analysis, the ${ }^{1} \mathrm{H},{ }^{13} \mathrm{C}$ and 2D (HMQC, HMBC, ${ }^{1} \mathrm{H}-{ }^{1} \mathrm{H}$ COSY) NMR data (Figure 5a, Supplementary Figures S14-S16), 2 was identified as the keto reduction product of 1. In NOESY spectrum, the cross peaks of $\mathrm{H}-1 / \mathrm{H}-8, \mathrm{H}-1 / \mathrm{H}-11 \alpha\left(\delta_{\mathrm{H}} 2.00\right), \mathrm{H}-1 / \mathrm{H}-15\left(\delta_{\mathrm{H}} 0.97\right), \mathrm{H}-7 / \mathrm{H}-9 \alpha\left(\delta_{\mathrm{H}} 1.81\right)$, H-8/H-9 $\alpha, \mathrm{H}-8 / \mathrm{H}-15\left(\delta_{\mathrm{H}} 0.97\right), \mathrm{H}-9 \alpha / \mathrm{H}-15$, and $\mathrm{H}-11 \alpha / \mathrm{H}-15$ revealed these protons were $\alpha$-oriented (Figure 5b, and Supplementary Figure S17). No cross peak was observed between H-7 and H-13 (Me) also supported that $\mathrm{H}-7$ and $\mathrm{H}-13$ were $\alpha$ and $\beta$-oriented, respectively. CD curve of 2 was similar with 1, except the absorption peak at $314.2 \mathrm{~nm}$ (Figure $3 \mathrm{~b}$ ). Based on the absolute configuration determination of $\mathbf{1}$, the absolute configuration of $\mathbf{2}$ was established as $1 R, 6 \mathrm{~S}, 7 \mathrm{~S}, 8 \mathrm{~S}$.

Figure 5. (a) ${ }^{1} \mathrm{H}-{ }^{1} \mathrm{H}$ COSY correlations (bold lines), the main HMBC correlations (arrows); and (b) key NOESY correlations for 2.

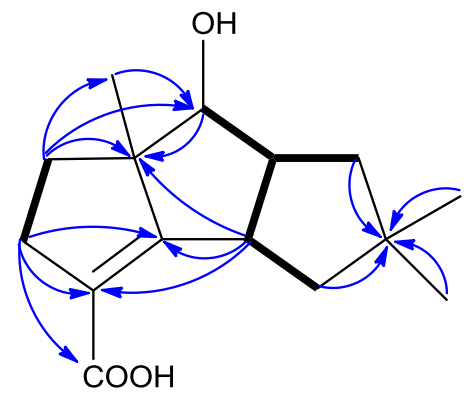

(a)

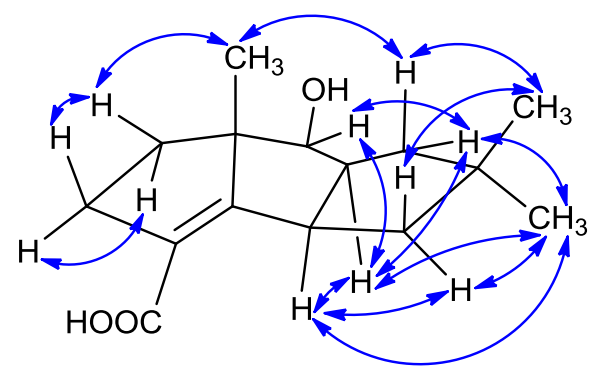

(b)

The human nasopharyngeal cancer cell line CNE-1 and CNE-2 were used to examine the cytotoxic activities of $\mathbf{1}$ and $\mathbf{2}$ in vitro. Compound $\mathbf{2}$ showed potent cytotoxic activities against $\mathrm{CNE}-1$ and CNE-2 cell lines with the $\mathrm{IC}_{50}$ values of 1.32 and $0.56 \mu \mathrm{M}$, respectively. By comparison, compound 2 displayed stronger cytotoxic activities than chondrosterin A (CNE-2: $4.95 \mu \mathrm{M})$, hirsutanol A (CNE-1: $10.08 \mu \mathrm{M}$; CNE-2: $12.72 \mu \mathrm{M}$ ), and incarnal (CNE-1: $34.13 \mu \mathrm{M}$; CNE-2: $24.87 \mu \mathrm{M})$. In contrast, 1 was inactive in this assay $\left(\mathrm{IC}_{50}\right.$ values $\left.>200 \mu \mathrm{M}\right)$.

\section{Experimental Section}

\subsection{General Experimental Procedures}

Preparative HPLC was performed using a Shimadzu LC-20AT HPLC pump equipped with an SPD-20A dual $\lambda$ absorbance detector and a Shim-pack PRC-ODS HPLC column $(250 \times 20 \mathrm{~mm})$. Optical rotations were measured using a Schmidt and Haensch Polartronic HNQW5 optical rotation spectrometer. CD spectra were measured on a JASCO J-810 circular dichroism spectrometer. IR spectra were recorded on a PerkinElmer Frontier FT-IR spectrophotometer. UV spectra were recorded on a Shimadzu UV-Vis-NIR spectrophotometer. 1D and 2D NMR spectra were recorded on a Bruker Avance II 400 spectrometer. The chemical shifts are relative to the residual solvent signals $\left(\mathrm{CDCl}_{3}\right.$ : $\delta_{\mathrm{H}} 7.26$ and $\delta_{\mathrm{C}} 77.0$; Acetone- $d_{6}: \delta_{\mathrm{H}} 2.05$ and $\left.\delta_{\mathrm{C}} 29.92\right)$. Mass spectra were obtained on a Thermo DSQ EI low-resolution mass spectrometer and a Thermo MAT95XP EI high-resolution mass spectrometer. X-ray diffraction data were acquired on a Bruker SMART APEX CCD X-ray single crystal diffractometer. 


\subsection{Fungal Strain and Culture Method}

Chondrostereum sp. was isolated from the inner tissue of a soft coral of the species Sarcophyton tortuosum collected from the Hainan Sanya National Coral Reef Reserve, China. This fungal strain was maintained in sterile aqueous solution of $15 \%(\mathrm{v} / \mathrm{v})$ glycerol at $-80{ }^{\circ} \mathrm{C}$. The fermentation medium was glycerol $10 \mathrm{~g}$, peptone $5 \mathrm{~g}$, yeast extract $2 \mathrm{~g}, \mathrm{CaCO}_{3} 1 \mathrm{~g}$, seawater $1 \mathrm{~L}$. The $\mathrm{pH}$ of the medium was adjusted to 7.5 by adding either $\mathrm{HCl}(1 \mathrm{~N})$ or $\mathrm{NaOH}(30 \%$, w/v) solution. The mycelia were aseptically transferred to $500 \mathrm{~mL}$ Erlenmeyer flasks containing $200 \mathrm{~mL}$ of the sterile liquid medium. The flasks were then incubated at $28^{\circ} \mathrm{C}$ on a rotary shaker $(120 \mathrm{rpm})$ for 20 days.

\subsection{Extraction and Isolation}

Sixty liters of liquid culture was filtered through cheesecloth. The culture broth was successively extracted three times with EtOAc. The EtOAc extract was concentrated by low-temperature rotary evaporation. The extract $(24.6 \mathrm{~g})$ was chromatographed on a silica gel column using petroleum ether-EtOAc (100:0-0:100) followed by EtOAc-MeOH $(100: 0-0: 100)$ as the eluent to afford 12 fractions (code Fr. 1-Fr. 12). Fr. 4 was further purified by RP-HPLC with a gradient of $\mathrm{H}_{2} \mathrm{O}-\mathrm{MeCN}$ (40:60 up to 0:100, v/v) to afford compounds $1(21 \mathrm{mg})$ and $2(12 \mathrm{mg})$.

Chondrosterin I (1): Colorless solid; $[\alpha]_{\mathrm{D}}^{20}-17.73$ (c 0.015, MeOH); UV (MeOH) $\lambda_{\max }(\varepsilon) 244 \mathrm{~nm}$ (9310), $219 \mathrm{~nm}$ (7344); IR (KBr) $v_{\max }$ 2956, 2920, 2851, 1736, 1673, 1648, 1464, 1434, 1371, 1334, 1281, 1266, 1209, 1119, 1077, 927, 905, 763, 719, $711 \mathrm{~cm}^{-1} ;{ }^{1} \mathrm{H}$ and ${ }^{13} \mathrm{C}$ NMR data, see Table 1; LREIMS $m / z$ 248, 233, 220, 204, 187, 174, 159, 147, 132, 119, 105, 77, 65, 55; HREIMS $m / z 248.1406[\mathrm{M}]^{+}$(calcd for $\mathrm{C}_{15} \mathrm{H}_{20} \mathrm{O}_{3}, 248.1407$ ).

Chondrosterin J (2): White solid; $[\alpha]_{\mathrm{D}}^{20}-9.11$ (c $\left.0.006, \mathrm{MeOH}\right) ; \mathrm{UV}(\mathrm{MeOH}) \lambda_{\max }(\varepsilon) 237 \mathrm{~nm}$ (14829); IR (KBr) $v_{\max } 3372,2952,2924,2866,1677,1463,1445,1422,1385,1366,1329,1279$, 1263, 1245, 1228, 1197, 1158, 1135, 1100, 1060, 1030, 1015, 971, 912, 811, 764, 691, $665 \mathrm{~cm}^{-1} ;{ }^{1} \mathrm{H}$ and ${ }^{13} \mathrm{C}$ NMR data, see Table 2. LREIMS $\mathrm{m} / \mathrm{z} 250,232,214,204,199,187,171,145,131,119,105$, 91, 77, 69, 55; HREIMS $m / z 250.1563[\mathrm{M}]^{+}$(calcd for $\mathrm{C}_{15} \mathrm{H}_{22} \mathrm{O}_{3}, 250.1563$ ).

\subsection{Crystal Structure Determination of $\mathbf{1}$}

Crystals of 1 was obtained from EtOAc solution. Chondrosterin I (1): $\mathrm{C}_{15} \mathrm{H}_{20} \mathrm{O}_{3}, M=248.31$, colourless block, orthorhombic system, space group $P 22_{1} 2_{1} 2_{1}, a=6.4797(2), b=8.3776(2)$, $c=50.4166(14) \AA, V=2736.83(13) \AA^{3}, Z=4, d=1.205 \mathrm{~g} / \mathrm{cm}^{3}$, crystal size $0.40 \times 0.38 \times 0.36 \mathrm{~mm}^{3}$. The flack parameter is 0.1648 . X-ray diffraction data were collected on a Bruker SMART APEX CCD diffractometer with $\mathrm{Cu} K_{\alpha}$ radiation $(\lambda=1.54178 \AA)$ at a temperature of $173 \mathrm{~K}$. The data were processed using CrysAlis. The structures were solved by direct method. H-atoms were added in ideal positions and refined as riding models. The structures were refined using full-matrix least-squares based on $F^{2}$ with program SHELXL $[7,8]$.

CCDC967610 contains the supplementary crystallographic data of compound 1 [9]. 


\subsection{Cytotoxicity Assay}

The in vitro cytotoxicities of $\mathbf{1}$ and $\mathbf{2}$ were determined using the colorimetric MTT (3-(4,5-dimethylthiazol-2-yl)-2,5-diphenyl- $2 H$-tetrazolium bromide) assay. The tested human nasopharyngeal carcinoma cell lines CNE-1 and CNE-2 were seeded in 96-well plates at a density of $3 \times 10^{7}$ cells $/ \mathrm{L}$, and the compounds were added at various concentrations $(0.0125-5 \mu \mathrm{g} / \mathrm{mL})$. After $48 \mathrm{~h}$, MTT was added to the culture medium at a final concentration of $0.5 \mathrm{mg} / \mathrm{mL}$, and the plates were incubated for $4 \mathrm{~h}$ at $37^{\circ} \mathrm{C}$. The supernatant was removed. The formazan crystals were dissolved in DMSO $(150 \mu \mathrm{L})$ with gentle shaking at r.t. The absorbance at $570 \mathrm{~nm}$ was recorded with a microplate reader (Bio-Rad, Hercules, California, CA, USA), and the data were analyzed with the SPSS 13.0 software package. Hirsutanol A was used as a positive control and it showed cytotoxic activities against CNE-1 and CNE-2 cell lines with the $\mathrm{IC}_{50}$ values of 10.08 and $12.72 \mu \mathrm{M}$, respectively.

\section{Conclusions}

Our results indicated that the marine fungus Chondrostereum sp. could produce novel metabolites with various structures. Hopefully, the systematical altering the component of the culture media can more fully explore the biosynthesis potential of this fungus. Compounds $\mathbf{1}$ and $\mathbf{2}$ belong to hirsutane sesquiterpenoids, and have some unique features, including a rearranged hirsutane skeleton which may be derived by migration of a methyl group from C-2 to C-6, a double bond between C-2 and C-3, and a carboxyl group connected to $\mathrm{C}-3$. To the best of our knowledge, the hirsutane sesquiterpenoids, complicatic acid [10], pleurotellic acid [11], phellodonic acid [12], chlorostereone [13] and hirsutic acid [14], have a carboxyl group in each molecule. However, the carboxyl group placed at C-3 is unprecedented.

\section{Acknowledgments}

This work was supported by the National Natural Science Foundation of China (No. 30973633 and J1103305), Guangdong Provincial Science and Technology Research Program (No. 2012A031100005), Guangzhou Science and Technology Research Program (No. 2011Y1-00036), the Fundamental Research Funds for the Central Universities (No. 11lgpy09), Special Financial Fund of Innovative Development of Marine Economic Demonstration Project (GD2012-D01-001), and the College Students' Innovative Training Programs of Guangdong Province (No. 1055812311).

\section{Conflicts of Interest}

The authors declare no conflict of interest.

\section{References}

1. Li, H.J.; Chen, T.; Xie, Y.L.; Chen, W.D.; Zhu, X.F.; Lan, W.J. Isolation and structural elucidation of chondrosterins F-H from the marine fungus Chondrostereum sp. Mar. Drugs 2013, $11,551-558$. 
2. Li, H.J.; Xie, Y.L.; Xie, Z.L.; Chen, Y.; Lam, C.K.; Lan, W.J. Chondrosterins A-E, triquinane-type sesquiterpenoids from soft coral-associated fungus Chondrostereum sp. Mar. Drugs 2012, 10, 627-638.

3. Li, H.J.; Lan, W.J.; Lam, C.K.; Yang, F.; Zhu, X.F. Hirsutane sesquiterpenoids from the marine-derived fungus Chondrostereum sp. Chem. Biodivers. 2011, 8, 317-324.

4. Yang, F.; Gao, Y.H.; Wu, K.W.; Deng, R.; Li, D.D.; Wei, Z.X.; Jiang, S.; Wu, X.Q.; Feng, G.K.; Li, H.J.; et al. A novel sesquiterpene hirsutanol A induces autophagical cell death in human hepatocellular carcinoma cells by increasing reactive oxygen species. Chin. J. Cancer 2010, 29, 655-660.

5. Yang, F.; Chen, W.D.; Deng, R.; Li, D.D.; Wu, K.W.; Feng, G.K.; Li, H.J.; Zhu, X.F. Hirsutanol A induces apoptosis and autophagy via reactive oxygen species accumulation in breast cancer MCF-7 cells. J. Pharmacol. Sci. 2012, 119, 214-220.

6. Yang, F.; Chen, W.D.; Deng, R.; Zhang, H.; Tang, J.; Wu, K.W.; Li, D.D.; Feng, G.K.; Lan, W.J.; Li, H.J.; et al. Hirsutanol A, a novel sesquiterpene compound from fungus Chondrostereum sp., induces apoptosis and inhibits tumor growth through mitochondrial-independent ROS production: Hirsutanol A inhibits tumor growth through ROS production. J. Transl. Med. 2013, 11, 32:1-32:10.

7. Sheldrick, G.M. SADABS: PROGRAM for Empirical Absorption Correction of Area Detector Data; University of Göttingen: Göttingen, Germany, 1996.

8. Sheldrick, G.M. SHELXTL 5.10 for Windows NT: Structure Determination Software Programs; Bruker Analytical X-ray Systems: Madison, WI, USA, 1997.

9. CCDC CIF Depository Request Form. Available online: http://www.ccdc.cam.ac.uk/cgi-bin/ catreq.cgi (accessed on 30 December 2013).

10. Mellows, G.; Mantle, P.G.; Feline, T.C.; Williams, D.J. Sesquiterpenoid metabolites from Stereum complicatum. Phytochemistry 1973, 12, 2717-2720.

11. Kupka, J.; Anke, T.; Giannetti, B.M.; Steglich, W. Antibiotics from basidiomycetes. XIV. Isolation and biological characterization of hypnophilin, pleurotellol, and pleurotellic acid from Pleurotellus hypnophilus (Berk.) Sacc. Arch. Microbiol. 1981, 130, 223-227.

12. Stadler, M.; Anke, T.; Dasenbrock, J.; Steglich, W. Antibiotics from basidiomycetes. XLII. Phellodonic acid, a new biologically active hirsutane derivative from Phellodon melaleucus (Thelephoraceae, Basidiomycetes). Z. Naturforsch C 1993, 48, 545-549.

13. Liermann, J.C.; Schüffler, A.; Wollinsky, B.; Birnbacher, J.; Kolshorn, H.; Anke, T.; Opatz, T. Hirsutane-type sesquiterpenes with uncommon modifications from three basidiomycetes. J. Org. Chem. 2010, 75, 2955-2961.

14. Comer, F.W.; McCapra, F.; Qureshi, I.H.; Scott, A.I. Structure and chemistry of hirsutic acid. Tetrahedron 1967, 23, 4761-4768.

(C) 2014 by the authors; licensee MDPI, Basel, Switzerland. This article is an open access article distributed under the terms and conditions of the Creative Commons Attribution license (http://creativecommons.org/licenses/by/3.0/). 